\title{
Struktur Komunitas Zooplankton Pada Kawasan Biorock di Perairan Gili Trawangan Lombok Utara
}

\author{
Ike Putri Desyana ${ }^{1}$, Suripto ${ }^{1}$, Hilman Ahyadi ${ }^{1}$, Lalu Japa ${ }^{2}$ \\ ${ }^{1}$ Dosen Jurusan Biologi FMIPA Universitas Mataram \\ ${ }^{2}$ Dosen Pendidikan Biologi FKIP Universitas Mataram \\ ljapa@unram.ac.id
}

\begin{abstract}
Abstrak
Zooplankton memiliki peran ekologis yang sangat penting di perairan termasuk pada kawasan biorock di perairan Gili Trawangan Lombok Utara. Penelitian ini dilaksanakan untuk mendapatkan gambaran tentang keanekaragaman dan komposisi jenis zooplankton pada kawasan biorock di perairan Gili Trawangan Lombok Utara. Pengambilan sampel zooplankton dilakukan pada 6 titik di kawasan biorock dan non biorock yang tersebar di perairan Gili Trawangan. Pengamatan dan identifikasi zooplankton dilakukan di Laboratorium Biologi Fakultas MIPA Universitas Mataram. Total zooplankton yang teridentifikasi pada kawasan biorock dan non biorock di perairan Gili Trawangan adalah 56 jenis yang tergolong dalam 6 kelas yaitu kelas Annelida dengan 2 famili ( 2 jenis), Arthropoda meliputi 19 famili (40 jenis), Chaetognatha dengan hanya 1 famili ( 2 jenis), Chordata yang terdiri dari 6 famili (8 jenis), Coelenterata dengan 3 famili (3 jenis) dan Mollusca yang terdiri atas 1 famili (1 jenis). Keanekaragaman jenis zooplankton pada kawasan biorock termasuk kategori sedang dan pada kawasan non biorock termasuk dalam kategori rendah. Jenis yang memiliki nilai penting tertinggi adalah Calanus sinicus.
\end{abstract}

Kata kunci : zooplankton, biorock, Gili Trawangan

\begin{abstract}
Zooplankton have some ecological importants in aquatic ecosystem including in the artificial habitat of biorock in the waters of Gili Trawangan Lombok Utara. A research was conducted in the biorock of Gili Trawangan for zooplankton community. Samplings were done at six sites in the biorock and nonbiorock area of Gili Trawangan waters. Laboratory observation and identification of zooplankton species was conducted in the Biology Laboratory of Science Faculty, University of Mataram. Total fivety six species of zooplankton were identified. The species were member of six classes: Annelide with two families and two species; Arthrophod with six families and eigth species; Chaetognathe with one family and two species; six families and eigth species of class Chordate; three families and three species for class of Coelenterate; and Mollusc with one family and one species. Species diversity of zooplankton in the areas of biorock and nonbiorock were intermediate and low categories, respectively. Calanus sinicus was a dominant species of zooplankton in that areas.
\end{abstract}

Keywords:Community,Zooplankton,Biorock,GiliTrawangan 


\section{Pendahuluan}

Gili Trawangan merupakan salah satu dari tiga pulau yang terdapat di Kabupaten Lombok Utara, Provinsi Nusa Tenggara Barat. Pulau ini terkenal dengan pulau yang indah di kalangan turis dan para penyelam. Oleh karena itu, banyak wisatawan yang berkunjung untuk menikmati keindahan pantainya. Ekosistem terumbu karang yang ada di perairan Gili Trawangan merupakan obyek wisata utama. Terumbu karang memiliki produktivitas dan keanekaragaman yang tinggi sehingga dapat berfungsi secara ekologis antara lain sebagai tempat pemijahan ikan (spawning ground), pembesaran (nursery ground) dan tempat mencari makan (feeding ground).

Menurut Riaman (2012), kerusakan terumbu karang di sekitar perairan Gili Trawangan mengalami kerusakan yang cukup parah sehingga diperlukan rehabilitasi dan pengawasan yang baik. Sebagian besar terumbu karang telah mengalami kerusakan diakibatkan oleh peristiwa alam (global warming), penebangan hutan, polusi, penurunan jangkar sembarangan dan penangkapan ikan secara destruktif serta kegiatan wisata bahari yang kurang memperhatikan lingkungan, (Robbe, 2010). Biorock merupakan suatu proses teknik rehabilitasi ekosistem terumbu karang yang berlangsung dalam laut, biasanya disebut juga dengan teknologi akresi mineral. Akresi mineral yang berlangsung di struktur biorock ini tidak hanya berpengaruh terhadap ekosistem terumbu karang tetapi mempengaruhi biota laut yang ada di sekitarnya termasuk plankton (Furqan, 2009).

Terumbu karang sangat erat hubungannya dengan komunitas biota yang ada di laut, seperti plankton khususnya zooplankton. Zooplankton disebut juga plankton hewani dan berperan sebagai konsumen pertama yang mentransfer energi dari produsen primer ke organisme yang lebih tinggi tingkatannya bahkan sampai ke tingkat profit manusia, sehingga terjadi aliran energi dalam rantai makanan. Melimpahnya fitoplankton dari kelas Bacillaripohyceae sangat baik untuk kehidupan zooplankton dan larva, dimana zooplankton itu sendiri merupakan sumber makanan yang penting bagi berbagai hewan zooplanktivor termasuk ikan (Syafara, 1996). Selain itu, zooplankton juga dapat mempengaruhi populasi fitoplankton dengan aktivitas makannya. Dalam hal ini secara tidak langsung produksi energi dari produsen (fitoplankton) akan sampai pada hewan yang tingkatan tropiknya lebih tinggi atau khususnya hewan-hewan zooplanktivor yang menjadi predator zooplankton. Oleh karena itu, secara teoritis kemelimpahan zooplankton seharusnya mengikuti pola kemelimpahan fitoplankton yang menjadi makanannya.

Zooplankton hanya dapat hidup dan berkembang dengan baik pada kondisi perairan yang sesuai. Perubahan yang terjadi pada suatu perairan akan mempengaruhi struktur komunitas zooplankton yang ada serta merupakan pengontrol bagi produksi primer fitoplankton. Kelimpahan zooplankton yang tinggi dapat dijadikan sebagai salah satu indikator bahwa kondisi perairan yang ada di daerah tersebut baik.

Berdasarkan kondisi ekosistem terumbu karang yang semakin menurun dan perkembangan informasi metode biorock yang semakin berkembang saat ini maka perlunya mengkaji pengaruh metode biorock terhadap keberadaan zooplankton. Mengingat juga pentingnya keberadaan zooplankton dalam ekosistem perairan maka perlu dilakukan penelitian mengenai jenis zooplankton yang terdapat pada kawasan biorock di perairan Gili Trawangan yang berada di 
Desa Gili Indah Kecamatan Pemenang, Kabupaten Lombok Utara, Provinsi NTB.

Berdasarkan latar belakang yang dikemukakan di atas, maka dapat dirumuskan masalah sebagai berikut :

1. Bagaimanakah keanekaragaman jenis zooplankton pada kawasan biorock

\section{Bahan dan Metode}

a. Sampling dan Pengamatan Sampel

Sampel penelitian deskriptif eksploratif ini dilakukan pada 6 titik yang tersebar pada kawasan biorock dan non biorock yang berada di Gili Trawangan Kabupaten Lombok Utara (Gambar 1).

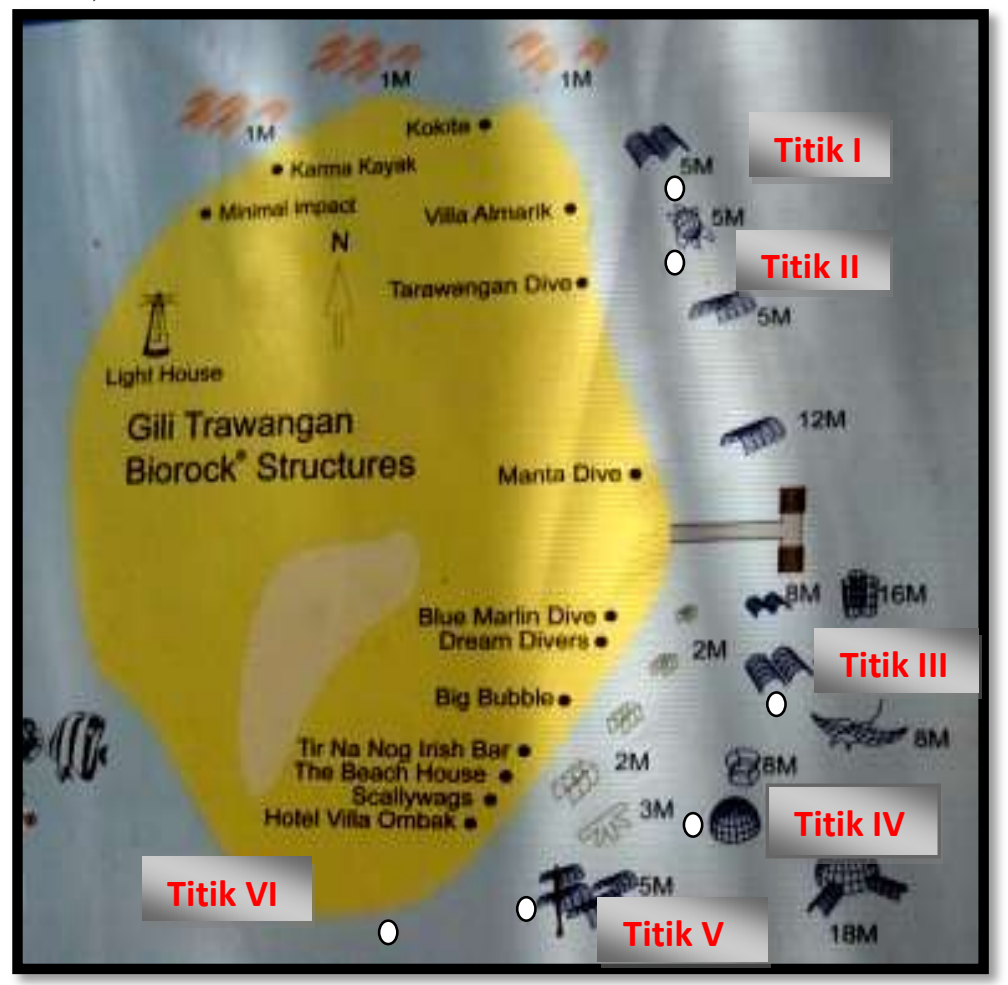

Gambar 1. Lokasi Pengambilan Sampel Pada Kawasan Biorock dan Nonbiorock Di Perairan Gili Trawangan Lombok Utara (Sumber: Robbe, 2010)

Keterangan :

Titik I : pada biorock yang berada di depan Villa Almarik

Titik II : pada biorock yang berada di depan Trawangan Dive

Titik III : pada biorock yang berada di depan Big Bubble

Titik IV : pada biorock yang berada di depan Beach House

Titik V : pada non biorock yang berada di depan Hari Puri

Titik VI: pada non biorock yang berada di depan Trawangan Resort

Pengambilan sampel dilakukan dengan menyaring air laut sebanyak 100 $\mathrm{L}$ dengan menggunakan jaring plankton bermata jaring 20 mikron. Sampel air dan non biorock di Perairan Gili Trawangan Lombok Utara?

Bagaimanakah komposisi zooplankton pada kawasan biorock dan non biorock di Perairan Gili Trawangan Lombok Utara? 
konsentrasi akhir pengawetan adalah $4 \%$

Pengamatan dan identifikasi
jenis zooplankton dilakukan di
Laboratorium Biologi Fakultas MIPA
Universitas Mataram. Sampel diamati di
bawah mikroskop dengan perbesaran
10x4 (40 kali) dan 10x10 (100 kali).
Identifikasi jenis zooplankton dilakukan
berdasarkan karakter morfologinya.
Identifikasi jenis dilakukan dengan
menggunakan buku petunjuk identifikasi
zooplankton dari Davis (1955) dan
Yamaji (1984).

\section{b. Analisis Data}

Perhitungan kepadatan jenis zooplankton, yang dinyatakan dalam jumlah individu per liter dihitung dengan menggunakan rumus dari Romimohtarto dan Juwana (2001). Keanekaragaman jenis zooplankton dihitung untuk mengetahui kualitas perairan dan perhitunganya pada masing-masing titik pengambilan sampel. Keanekaragaman jenis zooplankton dihitung dengan menggunakan indeks keanekaragaman jenis ( $\left.H^{\prime}\right)$ zooplankton yang ditentukan dengan mengacu pada indeks ShannonWienner dalam Barus (2002). Indeks keanekaragaman jenis ini kemudian disesuaikan dengan kisaran nilai indeks keanekaragaman jenis (H') modifikasi Prawiradilaga et al., (2003), seperti pada Tabel 1. Penentuan nilai penting (NP) untuk mengetahui jenis yang paling mendominasi di suatu tempat. Perhitungan ini dilakukan dengan menggunakan rumus dari Curtis dan Cottan (1964) dalam Surasana dan Taufikurrahman (1993).

Tabel 1. Kisaran Indeks Keanekaragaman

\begin{tabular}{ccl}
\hline No. & Nilai $\left(\mathrm{H}^{\prime}\right)$ & \\
\hline 1. & $0-1$ & Keanekaragaman sangat rendah \\
2. & $1-2$ & Keanekaragaman rendah \\
3. & $2-3$ & Keanekaragaman sedang \\
4. & $3-4$ & Keanekaragaman tinggi \\
5. & $>4$ & Keanekaragaman sangat tinggi \\
6. & 5 & Keanekaragaman maksimum \\
\hline
\end{tabular}

\section{Hasil dan Pembahasan}

Zooplankton yang teridentifikasi pada kawasan biorock dan non biorock di perairan Gili Trawangan adalah sebanyak 56 jenis yang tergolong dalam 6 filum yaitu filum Annelida, Arthropoda, Chaetognatha, Chordata, Coelenterata dan Mollusca, berturut-turut masingmasing dengan 2 famili ( 2 jenis), 19 famili (40 jenis), 1 famili ( 2 jenis), 6 famili ( 8 jenis), 3 famili ( 3 jenis), dan 1 famili ( 1 jenis). Total zooplankton yang teridentikasi pada kawasan biorock di perairan Gili Trawangan ini lebih tinggi dibandingkan 41 jenis di perairan Teluk Serewe Lombok Timur (Salmiah, 2004).
Jumlah jenis dari filum Arthropoda yang ditemukan pada kawasan biorock di perairan Gili Trawangan lebih banyak dibandingkan dengan anggota dari filum yang lainnya. Hal ini juga berbeda dengan penelitian yang dilakukan oleh Salmiah (2004) yang menemukan bahwa di perairan Teluk Sewere didominasi oleh famili Tintinnidae dan genus Tintinnopsis dari filum Protozoa. Anggota dari filum Arthropoda terbanyak dari kelas Copepoda seperti genus Acartia dan Calanus. Hal ini sesuai dengan yang dilaporkan Nybakken (1992, bahwa sebagian besar organisme zooplankton adalah dari anggota filum Arthropoda dan Copepoda merupakan kelas zooplankton 
yang mendominasi di laut. Sachlan (1978) juga menambahkan bahwa dalam ekosistem perairan Copepoda merupakan zooplankton yang dominan dengan populasi mencapai $70-90 \%$. Copepoda berperan sebagai mata rantai yang sangat penting antara produsen primer fitoplankton dengan karnivora.

Berdasarkan data individu masing-masing jenis menunjukkan bahwa pada titik III memiliki jumlah individu yang paling banyak yaitu 54 jenis dan jumlah individu yang paling sedikit terdapat pada titik VI yaitu 3 jenis (Gambar 2). Menurut Davis (1955) dalam Manullang (2004), adanya jumlah individu zooplankton yang berlimpah pada suatu titik sedangkan titik yang lain di perairan yang sama memiliki jumlah zooplankton yang sedikit menunjukkan bahwa distribusi horizontal zooplankton di suatu perairan tidak merata.

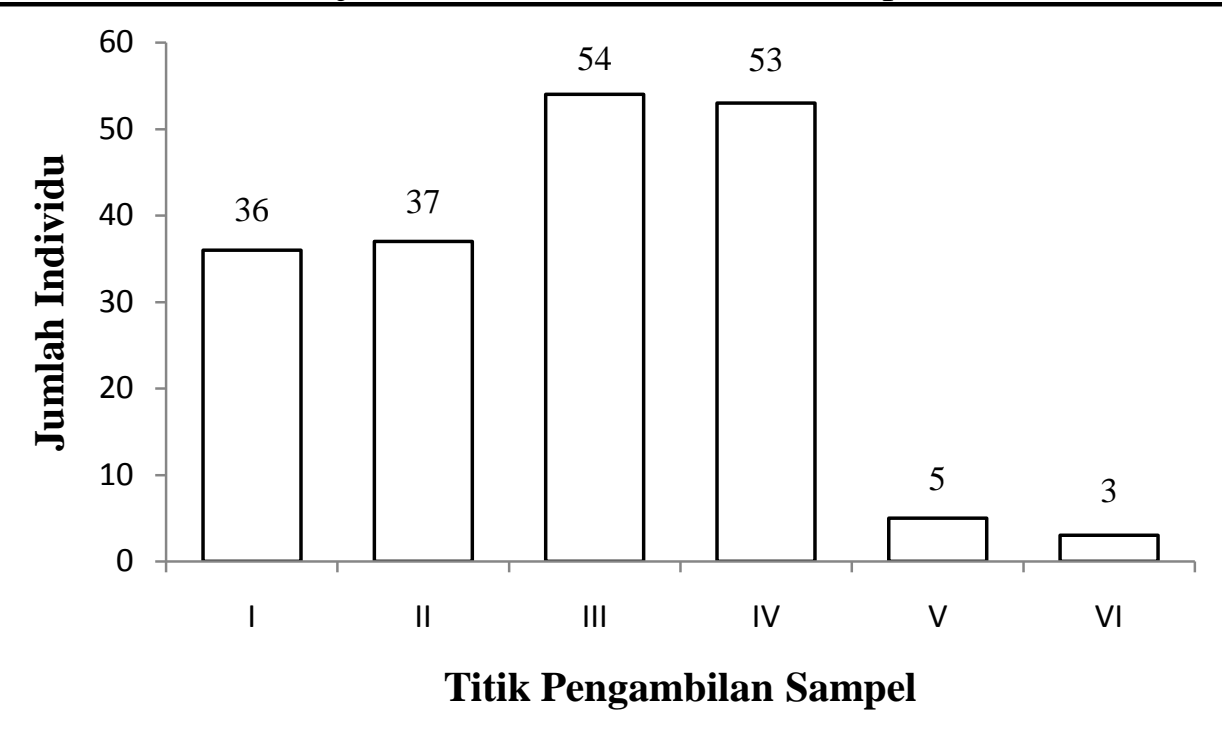

Gambar 2. Jumlah Individu Zooplankton Pada Masing-Masing Titik Pengambilan Sampel.

Indeks keanekaragaman jenis (H') zooplankton pada kawasan biorock di perairan Gili Trawangan dihitung dengan menggunakan rumus Indeks ShannonWienner. Indeks keanekaragaman jenis zooplankton berkisar antara 1,099 -
3,007. Indeks keanekaragaman tertinggi terdapat pada titik III $(3,007)$ dan terendah terdapat pada titik VI $(1,099)$. Perbandingan indeks keanekaragaman jenis zooplankton pada masing-masing titik dapat dilihat pada (Gambar 3). 


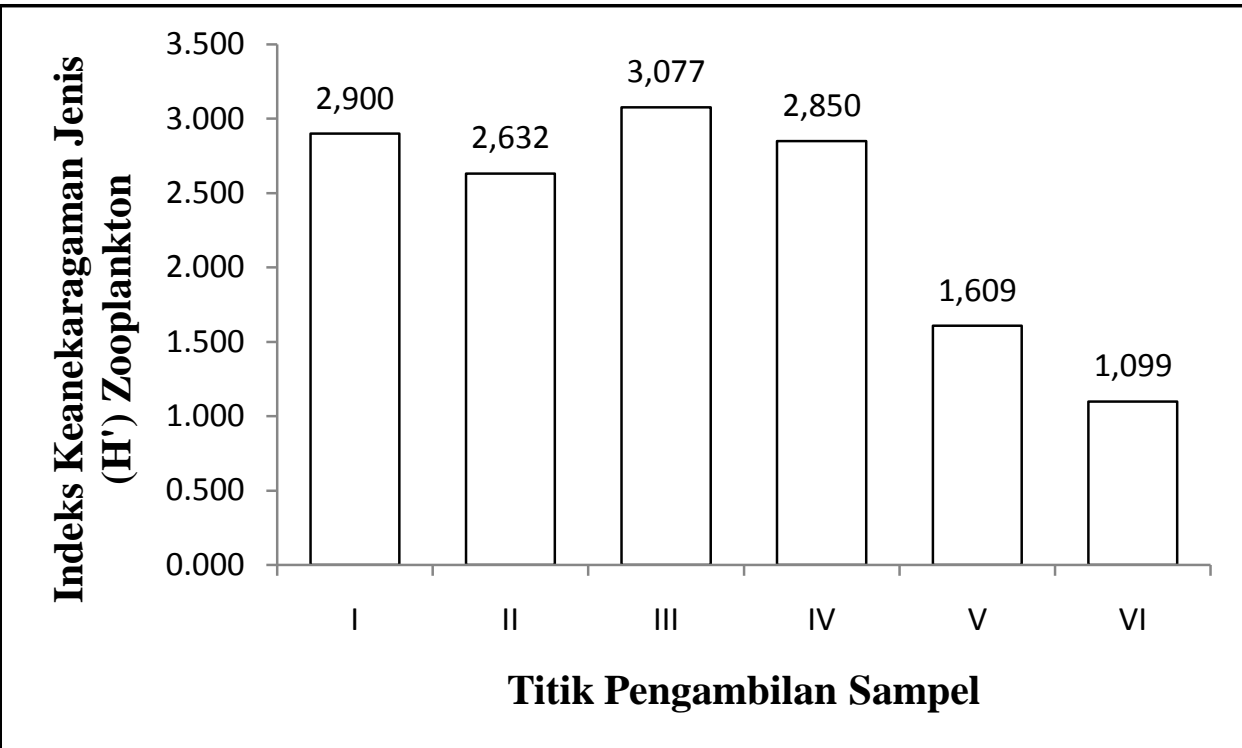

Gambar 3. Perbandingan Nilai Indeks Keanekaragaman Jenis (H') Zooplankton Antar Titik Pada Kawasan Biorock Di Perairan Gili Trawangan.

Pada (Gambar 3) terlihat bahwa titik I memiliki indeks keanekaragaman jenis sebesar 2,900; titik II 2,632; titik III 3,007; titik IV 2,850; titik V 1,609 dan titik VI 1,099. Titik I, II, III dan IV merupakan kawasan biorock sedangkan titik V dan VI merupakan kawasan non biorock. Indeks keanekargaman jenis zooplankton di perairan Gili Trawangan termasuk dalam kategori sedang untuk kawasan biorock berkisar 2-3 dan rendah untuk kawasan non biorock yang berkisar 1-2 berdasarkan Prawiradilaga et al., (2003).

Indeks keanekaragaman jenis zooplankton berhubungan dengan jumlah jenis dan jumlah individu per liter (kepadatan). Sejalan dengan ini, Kaswadji (1976) menjelaskan, semakin tinggi jumlah jenis yang ditemukan maka nilai indeks keanekaragamannya semakin tinggi pula atau dengan kata lain, jumlah jenis berbanding lurus dengan nilai indeks keanekaragaman jenis.

Tingginya keanekaragaman jenis zooplankton yang terdapat pada titik III dapat disebabkan oleh keberadaan fitoplankton sebagai sumber makanan zooplankton, dimana pada penelitian Akmala (2011) melaporkan bahwa pada titik yang sama di perairan Gili Trawangan jumlah jenis zooplankton yang diperoleh cukup besar yakni 30 jenis.

Berdasarkan dari hasil pengamatan yang telah dilakukan, komposisi jenis zooplankton dimana kelas Arthropoda merupakan filum yang mendominasi komposisi dan kelimpahan jenis zooplankton, diikuti oleh Chordata sedangkan untuk filum Chaetognatha dan Mollusca merupakan divisi yang mempunyai komposisi dan kelimpahan jenis terkecil. Anggota Arthropoda khususnya Copepoda yang mendominasi pada setiap titik pengambilan sampel. Arinardi et al. (1997) dalam Trimaningsih (2008) menambahkan bahwa populasi Copepoda di berbagai habitat akuatik mempunyai nilai kelimpahan dan komposisi yang bervariasi, tergantung pada kondisi lingkungan.

Jenis yang memiliki nilai penting tertinggi adalah Calanus sinicus yakni $148,022 \%$ dan hampir ditemukan pada setiap titik pengambilan sampel. Adapun jenis yang memiliki nilai penting tertinggi pada setiap titik pengambilan sampel adalah Calanus hyperboreus 
$(22,540 \%)$, kemudian disusul oleh Acartia hudsonica (19,679 \%), Lucifer sp. dan Mysidae's larva (16,900 \%) untuk titik I. Jenis yang memiliki nilai penting tertinggi pada titik II adalah Calanus divergens $(26,474 \%)$, kemudian disusul oleh Calanus hyperboreus (21,069 \%), Calanus marshallae dan Calanus valgars $(18,501 \%)$. Pada titik III jenis zooplankton yang memiliki nilai penting tertinggi adalah Mysidae's larva $(23,154 \%)$, kemudian disusul oleh Eucalanus sp. (21,302 \%) dan Acartia hudsonica $(17,419 \%)$. Pada titik IV jenis zooplankton yang memiliki nilai penting tertinggi adalah Calanus hyperboreus $(25,504 \%)$, kemudian disusul oleh Calanus sinicus (21,543 \%), Mysidae's larva dan Sagitta enflata (17,769 \%). Sementara itu, pada titik V tidak ada jenis zooplankton yang memiliki nilai penting tertinggi melainkan nilai penting tiap jenisnya sama yaitu $(40,000 \%)$. Begitu pula pada titik VI juga setiap jenis memiliki nilai penting yang sama yaitu $(66,667 \%)$.

Setiap jenis zooplankton memiliki kadar toleransi yang berbeda terhadap kondisi fisika kimia perairan untuk dapat tumbuh dan berkembang. Kepadatan zooplankton di perairan dipengaruhi oleh faktor fisika dan kimia perairan diantaranya: faktor fisika (suhu, kecerahan, kedalaman dan arus) serta faktor kimia (oksigen terlarut, karbondioksida, $\mathrm{pH}$, salinitas dan nutrien) (Raymond 1963 dalam Prianto et al., 2010).

Kepadatan total zooplankton di perairan Gili Trawangan diperoleh sebesar 313,349 Ind/L. Kepadatan tertinggi dimiliki oleh jenis Calanus hyperboreus sebesar 28,334 Ind/L. Calanus hyperboreus adalah salah satu spesies dari ordo calanoida yang penting dalam rantai makanan di lautan karena jumlahnya berlimpah, kosmopolit dan distribusinya merata sehingga menjadikannya sebagai salah satu rantai makanan. Calanidae sangat penting bagi protozoa yang berukuran kecil sampai ikan besar bahkan bagi beberapa jenis ikan paus (Boltovskoy et al., 1991 dalam Media et al., 2007).

Jenis yang memiliki kepadatan tertinggi pada titik I adalah Acartia hudsonica dan Calanus hyperboreus dengan nilai yang sama (6,667 Ind/L), kemudian disusul oleh Lucifer sp. dan Mysidae's larva (5,000 Ind/L). Pada titik II jenis zooplankton yang memiliki kepadatan tertinggi adalah Calanus divergens $(10,000 \quad \mathrm{Ind} / \mathrm{L}), \quad$ Calanus hyperboreus $\quad(6,667 \quad \mathrm{Ind} / \mathrm{L}) \quad \mathrm{dan}$ Anchiphimedia dorsalis (5,000 Ind/L). Sementara itu, jenis yang memiliki kepadatan tertinggi pada titik III yaitu Mysidae's larva (11,667 Ind/L), Eucalanus sp. (10,000 Ind/L) dan Acartia hudsonica $(8,333 \mathrm{Ind} / \mathrm{L})$. Jenis pada titik IV yang mempunyai kepadatan tertinggi adalah Calanus hyperboreus (13,333 Ind/L), kemudian disusul oleh Mysidae's larva dan Sagitta enflata (8,333 Ind/L) serta Calanus giacialis (5,000 Ind/L). Sedangkan pada titik V dan VI masingmasing jenis zooplankton mempunyai kepadatan yang sama yaitu 1,667 Ind/L.

Kepadatan zooplankton yang terdapat di perairan didukung oleh ketersediaan fitoplankton sebagai makanannya. Semakin tinggi kepadatan zooplankton diduga dipengaruhi oleh adanya fitoplankton yang merupakan makanan utama zooplankton. Fitoplankton mempunyai peranan sebagai produsen yang merupakan sumber energi bagi kehidupan organisme lainnya. Hal ini juga didukung oleh Arinardi (1977) yang menyatakan bahwa kepadatan zooplankton sangat tergantung pada kepadatan fitoplankton, karena fitoplankton adalah makanan bagi zooplankton, dengan demikian kuantitas atau kelimpahan zooplankton akan tinggi di perairan yang tinggi kandungan fitoplanktonnya. 
Pada penelitian sebelumnya Akmala (2011) melaporkan bahwa kepadatan total fitoplankton pada kawasan biorock di perairan Gili Trawangan sebesar 1152.667 Ind/L. Nilai ini lebih besar dari kepadatan total zooplankton di perairan yang sama.

\section{Kesimpulan}

Berdasarkan penelitian yang telah dilakukan, maka dapat disimpulkan bahwa:

1. Total zooplankton yang teridentifikasi pada kawasan biorock di perairan Gili Trawangan adalah sebanyak 56 jenis yang tergolong dalam enam filum yaitu filum Annelida, Arthropoda, Chaetognatha, Chordata, Coelenterata dan Mollusca.

2. Keanekaragaman jenis zooplankton pada kawasan biorock termasuk kategori sedang dan pada kawasan non biorock termasuk dalam kategori rendah.

3. Jenis yang memiliki nilai penting tertinggi adalah Calanus sinicus.

\section{Daftar Pustaka}

Akmala, N. 2011. Studi Keanekaragaman Fitoplankton Pada Kawasan Biorock di Perairan Gili Trawangan Kecamatan Pemenang Kabupaten Lombok Utara. Skripsi, S1 Program Studi Biologi, Fakultas MIPA. Universitas Mataram. Mataram.

Arinardi, O.H. 1977. Hubungan Antara Kuantitas Fitoplankton dan Zooplankton di Perairan Sebelah Utara Gugus Pulau Pari, Kepulauan Seribu. Oseanologi di Indonesia. Vol. 11:73-85.

Barus, I.T.A. 2002. Pengantar

Limnologi. Direktorat Pembinaan

Penelitian dan Pengabdian pada Masyarakat, Direktorat Jenderal Penelitian Tinggi, Medan.
Davis, C.C. 1955. The Merine And Fresh Water Plankton. Chicago, Michigan State University Press.

Furqan, R. 2009. Biorock Technology Sebagai Salah Satu Alternatif Upaya Rehabilitasi Ekosistem Terumbu Karang. Sekolah Tinggi Perikanan. Jakarta.

Kaswadji, R. 1976. Keterkaitan Ekosistem di Dalam Wilayah Pesisir. Fakultas Perikanan dan Kelautan IPB. Bogor.

Manullang, M. P. 2004. Kelimpahan dan Distribusi Spasial Zooplankton di Perairan Sekitar Keramba Jaring Apung di Waduk I.R. H. Juanda Purwakarta, Jawa Barat. Skripsi, S1 Departemen Manajemen Sumberdaya Perairan Fakultas Perikanan dan Ilmu Kelautan, IPB. Bogor.

Media, F. I.N., Gede S.S., Adi H. dan Sudarto. 2007. Keanekaragaman dan Migrasi Vertikal Copepoda di Teluk Sumberkima Bali. Jurnal Riset Akuakultur Vol 3 No. 3 : 375-383.

Nybakken, J.W. 1992. Biologi Laut, Suatu Pendekatan Ekologi. Gramedia. Jakarta.

Prawiradilaga, D.M., A. Suryanto, W.A. Noerdjito, A. Saim, Purwaningsih, I. Rahmatika, S. Susiarti, Sidik, A. Marakarmah, A. Mun'im, M.H. Sinaga, E. Cholik, Ismail, M. Maharani, Y. Purwanto dan E. B. Waluyo. 2003. Final Reports and Biodiversity of Tesso Nilo Research Center for Biology SIPI and WWF Indonesia.

Prianto, E., Siswant K., dan Solekha A. 2010. Struktur Kominitas Zooplankton di Estuaria Pantai Timur Sumatera. Prosiding Seminar Nasional Limnologi V tahun 2010.

Riaman, Y. 2012. Memprihatinkan Kondisi Terumbu Karang dan 
Penyu di Tiga

Gili.http://www.mediaindonesia.c om/read/2012/04/15/313000/290/

101/memprihatinkan-

Kondisi_Terumbu-Karang-dan-

Penyu-di-Tiga-Gili. (Diakses: 15 April 2012).

Robbe, D. 2010. Gili Biorock ProjectSituation. Gilh Eco Trust. http://www.giliecotrust.com

Romimuhtarto, K. dan Juwana, S. 2001. Biologi Laut: Ilmu Pengetahuan Tentang Biologi Laut. Djambatan: Jakarta.

Sachlan, M. 1978. Planktonologi. Direktorat Jendral Perikanan, Departemen Pertanian. Bogor.

Salmiah, B. 2004. Kajian Komunitas Zooplankton Pada Musim Kemarau di Perairan Teluk Serewe Lombok Timur. Skripsi, S1 Program Studi Biologi FKIP, UNRAM. Mataram.

Surasana dan Taufikurrahman. 1993. Penuntun Praktikum Ekologi Tumbuhan. Jurusan Biologi Fakultas MIPA. Institut Teknologi Bandung: Bandung.

Syafara. 1996. Kemelimpahan dan

Keanekaragaman Fitoplankton di

Perairan Pantai Trikora, Pulau

Bintan. Jurnal Penelitian

Perikanan Indonesia. Vol II No.1

: 60-75.

Trimaningsih. 2008. Peranan dan

Distribusi Kopepoda di Laut.

Jurnal Warta Oseanografi. Vol XXII No. 2: April-Juni.

Yamaji, I. 1984. Illustration of The Marine Plankton of Japan, $3^{\text {rd }}$ edition. Hoskusha Publishing Co.Itd.Japan. 